Can anyone state from actual experience whether poisoning occurs from conveyance by wind, and whether dermatitis tends to occur a year later without fresh exposure? Both of these claims seem absurd, and yet $I$ am credulous enough to accept ary statement, however absurd, it it can artually be provedand some things that have seemed absolutely absurd have been proved.

A. L. Benedict, M.D.

Cincinnati, Ohio, March 16, 1906.

To the Editor:-In the current issue of THE Journal A. W. - Balch, Washington, passed assistant surgeon, United States Navy, takes exception to my article on "Dermatitis Venenata," abstracted in TuE Journac. He says that while I have had Rhus toxicodendron poisoning twice he has had it eighty times. He queries: "Is it possible that the work of Pfaff is not yet known to the profession?" Had he read the original of my article, not the abstract, he would have seen full reference to Pfaff and his work. I should be pleased to read Dr. Balch's experiences with his eighty cases of poisoning from Rhus toxicodendron more fully written up.

E. S. MCKEE, M.D.

\section{Quinin in Pneumonia.}

New Ricirmond, OHio, March 16, 1906.

T'o the Lditor:- In 1874 I read, at a meeting of the Amer1can Medical Society in Cincinnati, my translation of an article from "Volkmann's klinische Vorträge," written by Jurgenson in 1872, in which he advocates the use of large doses of quinin in the treatment of pneumonia in conjunction with cold water baths. He gave from 25 to 40 grains at one dose, or if this was not advisable owing to an idiosynerasy of the patient, he divided the dose in three or four equal portions, giving each at intervals of fifteen or twenty minutes, but so that the entire quantity was taken within an hour, or the reduction of temperature would not take place. I followed out this quinin treatment for two years, but found tha ${ }^{\perp}$ it did not influence the course of pneumonia either favorably or otherwise, and it was often followed by such unpleasant symptoms of cinchonism that $I$ desisted, and have not used the method since.

R. F. Erdman, M.D.

\section{Staining of Conjunctiva by Argyrol.}

Dover, N. H., Feb. 28, 1906.

To the Editor:-In a pamphlet sent out by the manufacturers of Argyrol I find the following statement: "Argyrol is the only silver salt that does not permanently stain the conjunetiva. It may be used with safety by patients themselves, as often as required."

Last week a patient appeared in my office who had been using a 10 per cent. solution of Argyrol in the left eye for nearly a year. It was originally prescribed by a competent oculist, but, of course, with the intention that it should only be used for a short time. I took pains to hunt up the original prescription to be sure that it was Argyrol.

In this case the bulbar conjunctiva, the caruncle, and the lining of the lid were as badly stained as from the prolonged use of a solution of nitrate of silver.

Louis W. Flanders.

\section{The Puxe-Food Bill Board of Experts.}

Ann Arbor, Mich., March 18, 1906.

To the Editor:-Your editorial stricture on the provision in the amendment to Section 9 of the Hepburn bill providing for the appointment of a board of experts to pass on the wholesomeness or unwholesomeness of preservatives would be just if it were true, but you were laboring under a misapprehension when you made your editorial statement. You say that the decision of the board is final and that there is no appeal to the courts or to the Secretary of Agriculture. This is all wrong. The board of experts is selected by the Secretary of Agriculture, and he is instructed by the law to appoint disinterested men; the Secretary fixes the compensation allowed members of the board and he may accept or reject their findings. The Secretary of Agriculture, and he alone, is given the authority to render decisions, and even his decisions are of no further value than for "the guidance of officials charged with the administration of food laws and for the information of courts." The statement that no appeal from the findings of the board can be made in the courts is too puerile to deceive anybody. In this country, no one, not even a food manu. facturer, can be convicted without a trial, and Section 6 of the Hepburn bill makes it plain that before any preservative can be condemned it must be shown by the prosecutor that it is poisonous or deleterious to health, and in such a trial the prosecutor and the defendant both have the right to bring forth whatever evidence each is able to produce. The findings of the board of experts as provided for in the amendment to Section 9 in such a trial may benefit either the prosecutor or the defendant, and either certainly would have the right to support or to combat the findings of such a board. The sole object in the amendment is to provide the Secretary of Agriculture with the best advice possible. A committee of agricultural chemists constitutes a suitable body for determining methods and standards for chemical analyses, but agricultural chemists are not fitted by their specialty to determine the effects of preservatives on the human body. It seems unnecessary to argue this point farther.

V. C. VAUGHAN.

[With all due respect to Professor Vaughan, and recognizing the fact that he is thoroughly conversant with the subject, we are still of the opinion that the clause to which we objected last week is vicious. Our readers, however, may judge for themselves. The clause will be found in section 9 of the bill, which was published last week.-Eo.]

\section{Miscellany}

The Record of the House.--Each house in Paris now has to have its sanitary record. It is something like a bank book or portfolio for each individual house. The cover bears the subdivision, ward, street and number, and inside is a small plan of the house, with designation of all drain pipes, cess pools, etc. A loose sheet contains a description of the house, anoiher contains a record of all the cases of communicable diseases that have occurred in the building, and the deaths from them, recorded as they occur. Another sheet records the disinfections done on the premises, with dates and causes. One or more sheets contain the record of the changes ordered by the bureau of hygiene, and the record of the compliance with these orders. One or more sheets further contain the results of sanitary inspection of the house. All these house books for one street are kept in an envelope or box, which has a record on the outside of the length and width of the street, number of houses, number of inhabitants, system of sewerage, water pipes, etc. P. Juillerat is chief of the bureau d'assainissement de l'habitation et du Casier sanitaire des maisons de Paris, and thus has charge of all this work. It is part of the police department. He describes its workings in the first number of Hygiène Générale et Appliquée, Jan., 1906, and discusses the expense of introducing a system of "house books" (casier sanitaire). A French law of 1902 ordered the formation of a bureau of hygiene in every town of 20,000 inhabitants or over, and he assumes that the officials of this burean will do the work necessary for the compiling of the records of each house. The first expense will not be much more than 1 wenty cents a house, and, once installed, the expense of maintenance will be trifling. The Paris authorities are much gratified at the way in which the system is working, although scarcely more than commenced there.

Fallacies in the Clinical Diagnosis of Gonorrhea.-Dr. G. Frank Lydston, Chicago, in a paper read before the Mississippi Valley Medical Association, said that the most dangerous type of infection of the female is that in which the external manifestations of the disease are absent or wanting. Gonorrheal urethritis in the female in the chronic form may present no secretion whatever on external examination. There may be little or no vaginal, cervical, or uterine discharge, and even such as there is may, on examination, fail to disclose the micro-organisms of gonorrhea. Notwithstanding this, the mucous glands may be involved, and under the influence of sexual excitement and the mechanical effect of coitus the 